\title{
Low self-esteem is related to depression and anxiety during recovery from an ectopic pregnancy
}

Sonia Hasani ${ }^{1}$, Eindra Aung ${ }^{2}$ and Mojgan Mirghafourvand ${ }^{3 *}$

\begin{abstract}
Background: Considering the increasing incidence of ectopic pregnancy and the negative effects of pregnancy loss on mental health, this study aimed to determine the status of mental health in women with ectopic pregnancy and examine its relationship with their self-esteem.

Methods: This was a cross-sectional study on 150 women (with a 100\% response rate) hospitalized for ectopic pregnancy et al.-Zahra hospital in Tabriz, Iran, during 2018-2019, and recruited via convenience sampling. Data were collected using the General Health Questionnaire-28, which has four subscales (overall score range: 0 to 84; subscale score range: 0 to 21 with a lower score indicating a better mental state), and Rosenberg Self-Esteem Scale (score range: -10 to +10 with a higher score indicating higher self-esteem). To determine the association between selfesteem and mental health, independent t-tests, and multivariable logistic regression were used.
\end{abstract}

Results: The response rate was 100\%. The mean score (SD) of participants' mental health was 31.4 (8.5), and that of self-esteem was 4.5 (3.80). The percentage of participants who were considered as having mental distress (i.e., overall GHQ-28 score $\geq 24$ ) was $76 \%$. Among the subscales of mental health, social dysfunction was the most prevalent (observed in $100 \%$ of the participants), followed by somatic symptoms (79.3\%). Lower self-esteem was significantly associated with overall mental distress (odds ratio (OR): 0.74; 95\% confidence interval (95\% Cl): 0.64-0.87; $P<0.001$ ), depression (OR: 0.70; 95\% Cl: 0.60-0.80; $P<0.001$ ) and anxiety/insomnia (OR: 0.76; 95\% Cl: 0.66-0.87; $P<0.001$ ).

Discussion: Mental distress was common among women with ectopic pregnancy. This study is the first to examine the relationship between self-esteem and mental health among women with ectopic pregnancy and highlights the important role of self-esteem in mental wellbeing among those women.

Keywords: Mental health, Self-esteem, Ectopic pregnancy, Women, Depression, Anxiety

\section{Background}

Pregnancy and the postpartum period are considered the most important events in a woman's life, and can also be among the most stressful life events regardless of the type of pregnancy or its outcome [1]. Pregnancy loss, resulting

\footnotetext{
*Correspondence: mirghafourvand@gmail.com

${ }^{3}$ Midwifery Department, Social Determinants of Health Research Center,

Faculty of Nursing and Midwifery, Tabriz University of Medical Sciences,

Tabriz, Iran

Full list of author information is available at the end of the article
}

from events such as medical termination, miscarriage, stillbirth, and ectopic pregnancy (EP), is commonly associated with grief and stress following the event [2]. Across the world, about $10 \%$ of pregnant women and $13 \%$ of women who have just given birth experience a mental disorder, most commonly depression. This is higher in developing countries, with $15.6 \%$ during pregnancy and $19.8 \%$ postpartum [3].

Ectopic pregnancy accounts for $1-2 \%$ of all pregnancies in various countries including the United States, and 
its incidence is increasing worldwide $[4,5]$. The prevalence of ectopic pregnancy is $0.5-1.5 \%$ of all first-trimester pregnancies in the United States. Approximately 95\% of ectopic pregnancies occur in different parts of the fallopian tube, and the remaining $5 \%$ are non-tubular and located in the ovaries, peritoneal cavity, cervix, or a previous cesarean section scar [6]. Ectopic pregnancies, although they account for a small proportion of pregnancies, indirectly account for $6 \%$ of all pregnancyrelated deaths [7]. Numerous studies have determined possible risk factors for ectopic pregnancy, including age, history of ectopic pregnancy, previous and current use of intra-uterine devices (IUDs), smoking, history of pelvic surgery, history of appendectomy, oral contraceptives (OCPs), Levonorgestrel-Emergency Contraceptive (LNG-EC), history of pelvic inflammatory disease, female sterilization, and infertility history [8-16]. Various studies have shown that pregnancy loss including ectopic pregnancy can negatively affect the mental health of mothers [19-21].

Mental health is a state of well-being in which an individual is aware of their potential abilities, can cope with natural life stresses, works productively and fruitfully, and can contribute to their community [17]. Women who have experienced stillbirth or child death are found to have lower self-esteem [22]. Self-esteem can be explained through three interrelated concepts: (1) positive or negative feelings about oneself in general, (2) feelings of selfworth in particular, and (3) self-evaluation of one's own characteristics, abilities, and attributes [18]. A study among post-partum mothers showed that those with low self-esteem were 39 times more likely to present with high-level depressive symptoms than those with high self-esteem, and that high self-esteem may compensate for the effects of stressful events [23]. Thus, self-esteem may be a critical internal resource, sustaining women during turbulent times [24-26]. Indeed, women with higher self-esteem have the internal strength to redirect or reinterpret stress and resist interpreting it negatively [26-28].

In recent years, an increase has been observed in the incidence of ectopic pregnancies [29]. Ectopic pregancy has a profound impact not only on physical health, often requiring urgent surgical treatment and carrying a risk of future infertility, but also on mental health, with previous research indicating a higher risk of post-traumatic stress disorder and suicide [30,31]. However, there are limited studies assessing the psychological impact of ectopic pregnancy and no study to date has examined the relationship between self-esteem and mental health in women with ectopic pregnancy. It seems that the impact of ectopic pregnancy on women's mental health can differ according to their self-esteem. The purpose of the current study was to determine the status of mental health (mental distress and symptoms of anxiety, insomnia, social dysfunction and depression) among women with ectopic pregnancy and the relationship of self-esteem and mental health in these women after losing their pregnancy. The results of the current study are expected to contribute to the body of knowledge of the psychological impact of experiencing an ectopic pregnancy, and also to the development of interventions targeting the promotion of self-esteem and mental health in women who suffer an ectopic pregnancy.

\section{Methods \\ Study design and participants}

Participants in this cross-sectional study were 150 women with EP, referred to the surgical ward of Al-Zahra hospital of Tabriz, Iran in 2018 and 2019. The inclusion criteria were women with ectopic pregnancy, according to their medical records, who were willing to participate in the study (100\% response rate). Women were excluded from the study if they had severe psychological problems, personality disorders, and psychiatric disorders; had experienced mental and psychological problems such as losing their loved ones in the last 6 months; had a history of taking psychiatric medication, including anti-anxiety and anti-depressant drugs before pregnancy; had a history of psychedelic drug use; and had a previous history of ectopic pregnancy with the loss of both of their fallopian tubes. Ten women with a previous ectopic pregnancy were excluded.

The sample size in this study was calculated using G-Power software based on the largest standard deviation of self-esteem $(0.66)$ from the study by Wonch Hill, with regard to 0.05 precision around the mean (3.32) [22], and the standard deviation of the mental health (11.5) from the study by Hasanpour, et al. with regard to 0.1 precision around the mean (29.7) [32]. The sample size required for a test power of $90 \%$ was 123 and 117 respectively. For the present study, considering the probable dropouts, 150 women were recruited into the study.

Convenience sampling was used. All participants were informed about the purpose of the study and assessed for eligibility according to the inclusion and exclusion criteria. If they were eligible to participate in the study and were willing to participate, written informed consent was obtained from them.

\section{Data collection}

Using a structured questionnaire, data were collected from the study participants in a face-to-face interview after completing their treatment for ectopic pregnancy et al.-Zahra Hospital, Tabriz. Data on socio-demographic and obstetric characteristics were collected, 
including questions on age, age of marriage, spouse's age, couple's level of education and job and adequacy of income, risk factors of EP, contraceptive method used, type of hospitalization, and the method of diagnosis and treatment provided.

Persian versions of the Rosenberg Self-Esteem Scale (RSES) and Goldberg's General Health Questionnaire (GHQ) were used in this study. The RSES is a 10-item instrument that measures self-esteem. The reliability and validity of the Persian version of RSES were confirmed in three studies in Iran with Cronbach's alpha coefficient ranging from 0.69 to 0.84 [33-35]. The version used in this study includes five positively stated items and five negatively stated items, rated on a twopoint scale with the item score of +1 for an "Agree" response and -1 for a "Disagree" response, the total score ranging from " -10 " to " +10 ", and the higher score indicating higher self-esteem.

The 28-item GHQ (GHQ-28) was used to assess participants' current mental health. Ebrahimi et al. examined the reliability and validity of the Persian version of the GHQ-28 in Iran and recommended that the questionnaire can be used as a screening tool in epidemiological studies of mental disorders [36]. It has also been tested among women with infertility in Iran [37]. The GHQ-28 has four subscales, which assess somatic symptoms (Items 1-7), anxiety/insomnia (Items 8-14), social dysfunction (Items 15-21), and severe depression (Items 22-28). Each subscale has 7 items, and each item is scored on a four-point Likert scale, with the item score ranging from 0 to 3 , the subscale score ranging from 0 to 21 , the overall score ranging from 0 to 84 , and a lower score indicating a better mental state. Participants who scored 6 or more in each subscale and 24 or more on the overall scale are considered to be suffering from mental distress.

\section{Statistical analyses}

Data were analyzed using SPSS for Windows (version 24; SPSS Inc., Chicago, IL., USA). To describe the socio-demographic characteristics, obstetric history, mental health and self-esteem, descriptive statistics were used consisting of frequency, percentage, mean, and standard deviation. The Pearson correlation test and independent $t$-test were used to explore the relationship of self-esteem with mental health and its subscales including somatic symptoms, anxiety/insomnia, social dysfunction, and severe depression. To confirm this relationship, logistic regression was used, adjusting for age and socio-economic status.

\section{Results}

The response rate of the participants was $100 \%$. The mean age in years (SD), age of marriage, and age of the spouse of women participating in this study were 29.9 (5.83), 21.5 (4.91), and 34.7 (5.84) respectively. More than one-third $(36.7 \%)$ of participants were college graduates and three-quarters of them (74.7\%) housewives. Also, $35.3 \%$ of spouses were college graduates and more than half $(60.0 \%)$ of the men had free jobs, such as taxi driver, barber, tailor, and other jobs that do not have any insurance. More than two-thirds (68.0\%) of participants stated that their family income for living expenses was adequate to some extent. Nearly all (91.3\%) of participants had only one marriage. Before their ectopic pregnancy, $52.6 \%$ and $77.3 \%$ have experienced at least one pregnancy and one delivery respectively, and one-fifth of participants had experienced an abortion. None of the patient characteristics or obstetric history differ between different mental health states (Table 1). Among the women who have participated in this study, $52 \%$ of them did not use any contraceptive methods. The mean (SD) of gestational age was 5.84 (1.49), and $42 \%$ of them were treated with methotrexate. Both of the fallopian tubes and the ovaries were retained in $70.7 \%$ of the participants, and only one fallopian tube and both of the ovaries were retained in $27.3 \%$ of them. The number of average days spent in the hospital ranged from 2 to 7 days.

The mean overall GHQ-28 score (SD) of the mental health of participants was 31.4 (8.5) with their scores ranging from 14 to 50 . Among the mental health subscales, the highest mean score (SD) was observed for the social dysfunction subscale [11.3 (1.6)], and the lowest score for the depression subscale [4.3 (3.9)]. The percentage of participants who were considered as having mental distress (i.e., overall GHQ-28 score $\geq 24$ ) was $76 \%$. Social dysfunction was the most prevalent (being observed in $100 \%$ of the participants), and somatic symptoms were the second most prevalent (79.3\%). The mean score of self-esteem (SD) of participants was 4.5 (3.8), with their scores ranging from -10 to +10 . Based on the results of the Pearson correlation test, self-esteem had a significant negative correlation with the total score of mental health $(\mathrm{r}=-0.40)$, anxiety $(\mathrm{r}=-0.25)$, social dysfunction $(\mathrm{r}=-0.27)$ and depression $(\mathrm{r}=-0.65)$ (Table 2).

According to findings from the independent $t$-test, mean RSES (self-esteem) scores of participants with mental distress were found to be significantly different from the mean RSES scores of those without mental distress $(\mathrm{t}(\mathrm{df})=3.57(148), \quad P<0.001)$. The mean RSES scores of participants with anxiety/insomnia were significantly lower than those without anxiety/insomnia $(\mathrm{t}(\mathrm{df})=3.79(148), P<0.001)$, and the mean RSES scores of participants with depression were significantly 
Table 1 Socio-demographic and obstetric characteristics of participants $(n=150)$

\begin{tabular}{|c|c|c|c|c|}
\hline \multirow[t]{2}{*}{ Characteristics } & \multirow[t]{2}{*}{ All participants } & \multicolumn{2}{|c|}{ Mental distress } & \multirow[t]{2}{*}{$P$ value \# } \\
\hline & & Yes* & No & \\
\hline Age (years) & & & & 0.15 \\
\hline$<25$ & $32(21.3)$ & $26(22.8)$ & $6(16.7)$ & \\
\hline $25-35$ & $93(62.0)$ & $66(57.9)$ & $27(75.0)$ & \\
\hline$>35$ & $25(16.7)$ & $22(19.3)$ & $3(8.3)$ & \\
\hline Mean (SD) & $29.9(5.83)$ & $30.1(6.06)$ & $29.4(5.08)$ & 0.52 \\
\hline \multicolumn{5}{|l|}{$\begin{array}{l}\text { Age of marriage } \\
\text { (years) }\end{array}$} \\
\hline Mean (SD) & $21.5(4.91)$ & $21.5(5.01)$ & $21.4(4.62)$ & 0.86 \\
\hline \multicolumn{5}{|l|}{ Spouse's age (years) } \\
\hline Mean (SD) & $34.7(5.84)$ & $34.8(6.31)$ & $34.4(4.03)$ & 0.71 \\
\hline Education & & & & 0.80 \\
\hline Illiterate & $2(1.3)$ & $2(1.8)$ & $0(0)$ & \\
\hline Elementary & $22(14.7)$ & $17(14.9)$ & $5(13.9)$ & \\
\hline Intermediate & $19(12.7)$ & $13(11.4)$ & $6(16.7)$ & \\
\hline Secondary & $3(2.0)$ & $3(2.6)$ & $0(0)$ & \\
\hline Diploma & $49(32.7)$ & $38(33.3)$ & $11(30.6)$ & \\
\hline College & $55(36.7)$ & $41(36.0)$ & 14 (38.9) & \\
\hline Occupation & & & & 0.73 \\
\hline Housewife & $112(74.7)$ & $85(74.5)$ & $27(75.0)$ & \\
\hline Working outdoor & $29(19.3)$ & $23(20.2)$ & $6(16.7)$ & \\
\hline Working indoor & $8(5.3)$ & $5(4.4)$ & $3(8.3)$ & \\
\hline Retired & $1(0.7)$ & $1(0.9)$ & $0(0)$ & \\
\hline Spouse's education & & & & 0.48 \\
\hline Elementary & $18(12.0)$ & $16(14.0)$ & $2(5.6)$ & \\
\hline Intermediate & $29(19.3)$ & $19(16.7)$ & $10(27.8)$ & \\
\hline Secondary & $5(3.3)$ & $4(3.5)$ & $1(2.8)$ & \\
\hline Diploma & $45(30.0)$ & $35(30.7)$ & $10(27.8)$ & \\
\hline College & $53(35.3)$ & $40(35.1)$ & $13(36.1)$ & \\
\hline $\begin{array}{l}\text { Spouse's occupa- } \\
\text { tion }\end{array}$ & & & & 0.32 \\
\hline Free job & $90(60.0)$ & 68 (59.6) & $22(61.1)$ & \\
\hline Employee & $40(26.7)$ & 33 (28.9) & $7(19.4)$ & \\
\hline Employer & $20(13.3)$ & $13(11.4)$ & $7(19.4)$ & \\
\hline $\begin{array}{l}\text { Adequacy of } \\
\text { income }\end{array}$ & & & & 0.84 \\
\hline Adequate & $102(68.0)$ & $78(68.4)$ & $24(66.7)$ & \\
\hline Inadequate & $48(32.0)$ & $36(31.6)$ & $12(33.3)$ & \\
\hline $\begin{array}{l}\text { Number of mar- } \\
\text { riages }\end{array}$ & & & & 0.55 \\
\hline 1 & $137(91.3)$ & $105(92.1)$ & $32(88.9)$ & \\
\hline 2 & $13(8.7)$ & $9(7.9)$ & $4(11.1)$ & \\
\hline $\begin{array}{l}\text { Number of preg- } \\
\text { nancies }\end{array}$ & & & & 0.87 \\
\hline 0 & $32(21.3)$ & $23(20.2)$ & $9(25.0)$ & \\
\hline 1 & $47(31.3)$ & $37(32.5)$ & $10(27.8)$ & \\
\hline 2 & $41(27.3)$ & $32(28.1)$ & $9(25.0)$ & \\
\hline$\geq 3$ & $30(20.0)$ & $22(19.3)$ & $8(22.2)$ & \\
\hline $\begin{array}{l}\text { Number of deliver- } \\
\text { ies }\end{array}$ & & & & 0.96 \\
\hline
\end{tabular}

Table 1 (continued)

\begin{tabular}{|c|c|c|c|c|}
\hline \multirow[t]{2}{*}{ Characteristics } & \multirow[t]{2}{*}{ All participants } & \multicolumn{2}{|c|}{ Mental distress } & \multirow[t]{2}{*}{$P$ value } \\
\hline & & Yes* & No & \\
\hline 0 & $45(30.0)$ & $35(31.0)$ & $10(28.6)$ & \\
\hline 1 & $71(47.3)$ & $54(47.8)$ & $17(48.6)$ & \\
\hline$\geq 2$ & $32(21.3)$ & $24(21.2)$ & 8 (22.9) & \\
\hline $\begin{array}{l}\text { Number of abor- } \\
\text { tions }\end{array}$ & & & & 0.77 \\
\hline 0 & $101(67.3)$ & 75 (65.8) & $26(72.2)$ & \\
\hline 1 & $30(20.0)$ & $24(21.1)$ & $6(16.7)$ & \\
\hline$\geq 2$ & $19(12.7)$ & $15(13.2)$ & $4(11.1)$ & \\
\hline $\begin{array}{l}\text { Ectopic pregnancy } \\
\text { history }\end{array}$ & & & & 0.91 \\
\hline Yes & $20(13.3)$ & $15(13.2)$ & $5(13.9)$ & \\
\hline No & $130(86.7)$ & 99 (86.8) & $31(86.1)$ & \\
\hline
\end{tabular}

Data are presented in $\mathrm{N}(\%)$ unless otherwise indicated

*Overall GHQ-28 score $\geq 24$

\# T-test for mean differences and chi-square test for differences in proportions

lower than those without depression $(\mathrm{t}(\mathrm{df})=6.31(148)$, $P<0.001)$. There was no significant difference between women with and without somatic symptoms in terms of RSES scores $(\mathrm{t}(\mathrm{df})=1.22(148), P=0.222$ ) (Table 3 ).

Univariate logistic regression analysis showed that for a one unit increase in RSES (self-esteem), there was a decrease in the odds of having mental distress (i.e., overall GHQ-28 score $\geq 24$ ) by $20 \%$ : unadjusted odds ratio (OR) of 0.8 with $95 \%$ confidence interval (CI) of 0.70 to $0.91(P=0.001)$ (Table 4). This association was found to be more statistically significant in the multivariable logistic regression model with an adjusted OR of 0.74 (95\% CI: $0.64-0.87 ; P<0.001)$. Self-esteem also had a statistically significant effect $(P<0.001)$ on having anxiety/insomnia (OR: 0.76; 95\% CI: 0.66-0.87), and depression (OR: 0.70; 95\% CI: $0.60-0.80)$, but had no such effect on somatic symptoms (OR: 0.88 ; 95\% CI: $0.77-1.01 ; P=0.062$ ).

\section{Discussion}

The results of our study showed that more than threefourths of women with EP had mental distress, which was found to be negatively associated with self-esteem of these women. In a clinical trial in Iran [38] examining the Progressive Muscle Relaxation Technique (PMRT), the mean pre-intervention score of GHQ-28 in primigravida women in the first trimester of low-risk pregnancy was comparable to the GHQ-28 score in our study, indicating that mental distress is prevalent among Iranian pregnant women in general. In other studies in Iran, less than 50\% of people older than 60 years [39] and $45 \%$ of nurses participating in the studies reported to have mental distress 
Table 2 Mental health status and its subdomains and self-esteem status in women with Ectopic Pregnancy $(n=150)$

\begin{tabular}{|c|c|c|c|c|}
\hline Variable & Mean $\left(\mathrm{SD}^{*}\right)$ & Obtainable score range & Obtained score range & $\begin{array}{l}\text { Correlation } \\
\text { with self- } \\
\text { esteem } \\
r(P)^{+}\end{array}$ \\
\hline Overall mental health score & $31.4(8.5)$ & $0-84$ & $14-50$ & $-0.40(<0.0001)$ \\
\hline Somatic symptoms & $7.9(2.7)$ & $0-21$ & $2-14$ & $-0.11(0.181)$ \\
\hline Anxiety/insomnia & $7.8(4.1)$ & $0-21$ & $0-17$ & $-0.25(0.002)$ \\
\hline Social dysfunction & $11.3(1.6)$ & $0-21$ & $6-15$ & $-0.27(0.001)$ \\
\hline Depression & $4.3(3.9)$ & $0-21$ & $0-16$ & $-0.65(<0.0001)$ \\
\hline Self-esteem & $4.5(3.8)$ & -10 to +10 & -10 to +10 & - \\
\hline
\end{tabular}

* Standard Deviation; ${ }^{\dagger}$ The results are based on Pearson Correlation test

Table 3 The prevalence of mental distress and its relationship with self-esteem $(n=150)$

\begin{tabular}{llll}
\hline Characteristics & Number (\%) & $\begin{array}{l}\text { Mean (SD*) of self- } \\
\text { esteem score }\end{array}$ & value $^{\dagger}$ \\
\hline Mental distress & $114(76.0)$ & $3.9(3.8)$ & $<0.001$ \\
Yes & $36(24.0)$ & $6.4(3.3)$ & 0.222 \\
No & $119(79.3)$ & $4.4(3.9)$ & \\
Somatic symptoms & $31(20.7)$ & $5.3(3.4)$ & $<0.001$ \\
Yes & & & \\
No & $101(67.3)$ & $3.8(4.0)$ & \\
Anxiety/insomnia & $49(32.7)$ & $6.2(2.9)$ & \\
Yes & & & \\
No & $150(100.0)$ & $4.5(3.8)$ & \\
Social dysfunction & $0(0.0)$ & $0.0(0.0)$ & \\
Yes & & & \\
No & $53(35.3)$ & $2.2(3.9)$ & \\
Depression & $97(64.7)$ & $5.8(3.0)$ & \\
Yes & & \\
No & & & \\
\hline
\end{tabular}

* Standard deviation; ${ }^{\dagger}$ The results are based on independent t-test
[40], compared to $76 \%$ of participants in our study reporting mental distress. On the other hand, research in the Northern England Urban community [41] showed that the total mean GHQ-28 score among 273 women in early pregnancy was much lower than that among women with EP in our study.

In our study, self-esteem was measured using the Rosenberg Self-Esteem Scale (RSES), and with a mean RSES score of 4.5 among study participants, their selfesteem was found to be slightly lower compared to other studies among Iranian women. A similar RSES score was observed in a clinical trial with Iranian women with EP reporting the mean baseline RSES score (SD) of 4.4 (4.3) in the control group. However, the RSES score (SD) of 5.1 (3.9) reported in the intervention group was slightly higher than that in our study [42]. Likewise, in a study among breastfeeding mothers in Iran, the mean RSES score (SD) was 5.8 (4.0) [43], which is higher than the RSES score in our study.

Previous research has shown that psychological and somatic symptoms can occur following the loss of

Table 4 Odds ratios of having mental distress, somatic symptoms, anxiety/insomnia or depression

\begin{tabular}{llrr}
\hline & Unadjusted OR (95\% Cl) & P value & Adjusted OR* (95\% Cl) \\
\hline Overall mental health score & $0.80(0.70-0.91)$ & 0.001 & $0.74(0.64-0.87)$ \\
Somatic symptoms & $0.93(0.83-1.04)$ & 0.222 & $0.88(0.77-1.01)$ \\
Anxiety/insomnia & $0.82(0.73-0.91)$ & $<0.001$ & $0.76(0.66-0.87)$ \\
Social dysfunction & N/A & & 0.062 \\
Depression & $0.74(0.66-0.83)$ & $<0.001$ & $0.70(0.60-0.80)$ \\
\hline
\end{tabular}

$95 \% \mathrm{Cl}=95 \%$ confidence interval; Adjusted $\mathrm{R}^{2}=38.4 \%$

\# $100 \%$ of participants have the subscale score at the cut-off point or higher for having social dysfunction

*adjusted for age, age of marriage, education status, occupation status, adequacy of income, number of pregnancies and history of ectopic pregnancy of participants, and spouse's age and education 
pregnancy and that the occurrence of psychological and somatic symptoms is higher in pregnancy loss or EP compared to normal pregnancy. The odds of moderate and severe depression (measured by The Major Depression Index (MDI)) among women with recurrent pregnancy loss in Denmark were found to be 5 times higher than those in women with normal pregnancy, and the incidence of self-reported stress was also higher in women with pregnancy loss [19]. A prospective cohort study among women with early pregnancy loss in London also found that at 1 month and 3 months after experiencing abortion or EP, $28 \%$ and $39 \%$ of the women respectively, fit into diagnostic criteria for post-traumatic stress disorder. That study also showed that women with EP suffered from higher levels of emotional stress, and were more likely to have symptoms of post-traumatic stress disorder, anxiety and depression than women who have experienced a miscarriage [44]. Findings from our study also suggest that the prevalence of mental distress (as measured by GHQ-28 instrument) in Iranian women with ectopic pregnancy is higher than that in the Iranian women in the general population (37.9\%) [45].

In this study, there was a negative correlation between self-esteem and mental health. The relationship of selfesteem with depression and anxiety is well-established in a variety of populations including college students, pregnant women, mothers, and other convenience and clinical samples [46]. However, a birth cohort study in New Zealand showed that low self-esteem scores were associated with a higher risk of mental health problems, although this relationship can be explained better with family and childhood factors (such as socioeconomic background and family functioning) rather than simply the effect of self-esteem [47]. Nevertheless, there is scant research on the relationship between self-esteem and mental health in pregnancy in particular $[26,28]$, and none in pregnancy loss or ectopic pregnancy. Limited research on this relationship in pregnancy showed that low self-esteem was associated with post-partum depression [28] and that self-esteem is considered one of the most important determinants of psychological problems in pregnancy [26]. Our study has added to the evidence base that this relationship also exists among women with ectopic pregnancy.

Experimental evidence suggests how self-esteem can be improved among women. For instance, a study on the Transactional Analysis training group (eight 90-min weekly sessions) showed that self-esteem of imprisoned women increased from low level to moderate level after attending educational classes [48]. Another study demonstrated the effect of three-component lifestyle intervention [49], that includes cognitive behavioral therapy (CBT) and life-style (food and exercise), on improving self-esteem. Counseling based on health promotion awareness [42] (through reducing ambiguities about EP) was also found to improve self-esteem in women with EP. In addition, a systematic review identified the effectiveness of compassion-focused therapies (CFT) or compassion-based interventions such as a CFTbased neurorehabilitation program, Compassionate Mind Training (CMT) programme, and compassionfocused interventions including general CBT principles and writing about stressful experiences following self-compassionate expressive writing instructions [50]. Previous studies have also shown that self-esteem, self-concept, and self-worth among children and adolescents can be improved through physical activity and exercise such as classroom aerobics with music [51-53]. Given the important role of self-esteem in the mental wellbeing among women who have experienced EP, as evident in our study, having the above services available to them and building their self-esteem during their childhood and adolescence may equip them with the ability to prevent or alleviate mental distress when facing adversities such as EP.

One limitation of our study was the absence of a control group. Previous studies $[19,20,44]$ on women with recurrent miscarriage and ectopic pregnancy included women with normal pregnancies as a control group. However, pregnant women might be experiencing specific alternations of mood which makes them a poor control group. In addition, the awareness of being pregnant is likely to affect the individual's mood, leading to women perhaps being less depressed and anxious than usual, or in some cases the reverse. Another limitation was that causal relationships cannot be established in our study due to its cross-sectional nature. In addition, data were collected after completing the treatment for ectopic pregnancy, immediately before the women were discharged from the hospital, therefore, it is suggested the mental health of these women be assessed after a few weeks, during which natural recovery has run its course.

Our results are relevant to healthcare professionals who provide care to women with EP. If our findings are supported by further studies using longitudinal or experimental designs, consideration should be given to screening of all women who have experienced an ectopic pregnancy for mental distress. Our findings suggest that improving self-esteem may buffer the negative effects of ectopic pregnancy on their mental health. Thus, incorporating assessment of self-esteem and mental health into the care of women with EP might benefit them, and implementation research is 
needed on how to effectively deliver services for promoting self-esteem and mental wellbeing among those women.

\section{Conclusion}

Mental distress is common among women with ectopic pregnancy. The present study highlights the important role of self-esteem in mental wellbeing among women with ectopic pregnancy, and shows that lower self-esteem is associated with poorer mental health. It is hoped that findings from this study will result in a heightened awareness among health providers to assess and improve self-esteem and mental health in women with ectopic pregnancy.

\section{Abbreviations}

SD: Standard deviation; EP: Ectopic pregnancy; IUDs: Intra-uterine devices; OCPs: Oral contraceptives; LNG-EC: Levonorgestrel-emergency contraceptive; RSES: Rosenberg self-esteem scale; GHQ: General health questionnaire; OR: Odds ratio; 95\% Cl: 95\% Confidence interval.

\section{Acknowledgements}

Our appreciation goes to the staff of the surgical ward of Al-Zahra Hospital of Tabriz. We would also like to thank all participants of this study and wish that those without children have some to their dreams.

\section{Authors' contributions}

$\mathrm{SH}$ involved in the conception and design, acquisition of data and drafting the manuscript. EA involved in the analysis of the data, interpretation of data and revising this manuscript. MM involved in the conception and design, interpretation of the data and writing this manuscript. All authors gave their final approval of this version to be published. All authors read and approved the final manuscript.

\section{Funding}

This Study was funded by Vice-chancellor for Research of Tabriz University of Medical Sciences. Funding source has not any role in the design of the study and collection, analysis and interpretation of data.

\section{Availability of data and materials}

The datasets used and analyzed during the current study are available from the corresponding author on reasonable request.

\section{Declarations}

\section{Ethics approval and consent to participate}

This study has been approved by the Ethics Committee of the Tabriz University of Medical Sciences (Code Number: IR.TBZMED.REC.1397.223). Written informed consent was obtained from each participant and also informed consent was obtained from the guardians of illiterate participants. All methods were carried out in accordance with relevant guidelines and regulations (Declaration of Helsinki).

\section{Consent for publication}

Not applicable.

\section{Competing interests}

The authors declare that they have no competing interests.

\section{Author details}

${ }^{1}$ Student Research Committee, Faculty of Nursing and Midwifery, Tabriz University of Medical Sciences, Tabriz, Iran. ${ }^{2}$ Department of Clinical Pharmacology and Toxicology, St Vincent's Clinical School, University of New South Wales, Kensington, Australia. ${ }^{3}$ Midwifery Department, Social Determinants of Health
Research Center, Faculty of Nursing and Midwifery, Tabriz University of Medical Sciences, Tabriz, Iran.

Received: 26 January 2021 Accepted: 30 August 2021

Published online: 08 September 2021

\section{References}

1. Burroughs A, Leifer G. Maternity nursing: an introductry text. 2001.

2. Kersting A, Kroker K, Schlicht S, Baust K, Wagner B. Efficacy of cognitive behavioral internet-based therapy in parents after the loss of a child during pregnancy: pilot data from a randomized controlled trial. Arch Womens Ment Health. 2011;14(6):465-77.

3. World Health Organization. maternal and child mental health. 2017. https://www.who.int/mental_health/maternal-child/en/\#

4. Farquhar CM. Risk factors. Lancet. 2005;366:583-91.

5. Stulberg DB, Cain LR, Dahlquist I, Lauderdale DS. Ectopic pregnancy rates and racial disparities in the Medicaid population, 2004-2008. Fertil Steril. 2014;102(6):1671-6.

6. Cunningham FG. Williams obstetrics. (C. Y. S. F. Gary Cunningham, Kenneth J. Leveno, Steven L. Bloom, Jodi S. Dashe, Barbara L. Hoffman, Brian M. Casey, Ed. 25th edition. New York: McGraw-Hill. 2018.

7. Peyman N, Ezzati Rastegar K, Tehrani H, Zarei F. Explanation of unwanted pregnancy from the pe rspective of family planning service providers: an exploratory study. Iran J Obstet Gynecol Infertil. 2016;19(12):18-26.

8. Ankum WM, Mol BWJ, Van der Veen F, Bossuyt PMM. Risk factors for ectopic pregnancy: a meta-analysis**Supported in part by grant OG 93/007 from the Ziekenfonds-Raad, Amstelveen. Fertil Steril. 1996;65(6):1093-9. https://doi.org/10.1016/s0015-0282(16)58320-4.

9. Barnhart KT, Sammel MD, Gracia CR, Chittams J, Hummel AC, Shaunik A. Risk factors for ectopic pregnancy in women with symptomatic firsttrimester pregnancies. Fertil Steril. 2006;86(1):36-43.

10. Bouyer J, Coste J, Shojaei T, et al. Risk factors for ectopic pregnancy: a comprehensive analysis based on a large case-control, population-based study in France. Am J Epidemiol. 2003;157(3):185-94. https://doi.org/10. 1093/aje/kwf190.

11. Chojenta C, Harris S, Reilly N, et al. Risk factors for ectopic pregnancy: a multi-center case-control study. BMC Pregnancy Childbirth. 2008;6(6):19. https://doi.org/10.1186/s12884-015-0613-1.

12. Coste J, Job-Spira N, Fernandez H, Papernik E, Spira A. Risk factors for ectopic pregnancy: a case-control study in France, with special focus on infectious factors. Am J Epidemiol. 1991;133(9):839-49.

13. Kamwendo F, Forslin L, Bodin L, Danielsson D. Epidemiology of ectopic pregnancy during a 28 year period and the role of pelvic inflammatory disease. Sex Transm Inf. 2000;76(1):28-32. https://doi.org/10.1136/sti.76.1. 28

14. Moini A, Hosseini R, Jahangiri N, Shiva MAM. Risk factors for ectopic pregnancy: a case-control study. J Res Med Sci Off J Isfahan Univ Med Sci. 2014;19(9):844-9.

15. Parashi S, Moukhah S, Ashrafi M. Main risk factors for ectopic pregnancy: a case-control study in a sample of Iranian women. Int J Fertil Steril. 2014;8(2):147-54.

16. Yuk J, Kim YJ, Hur J, Shin J. Association between socioeconomic status and ectopic pregnancy rate in the Republic of Korea. Int J Gynecol Obstet. 2013;122(2):104-7.

17. World Health Organization. Mental health. 2014. https://www.who.int/ mental_health/evidence/atlas/mental_health_atlas_2014/en/

18. Brown JD, Marshall MA. The thee faces of self-esteem. W: MH Kernis (red.), Self-esteem: Issues and answers (s. 4-9). New York: Psychology Press (2006).

19. Kolte AM, Olsen LR, Mikkelsen EM, Christiansen OB, Nielsen HS. Depression and emotional stress is highly prevalent among women with recurrent pregnancy loss. Hum Reprod. 2015;30(4):777-82.

20. Toffol E, Koponen P, Partonen T. Miscarriage and mental health: results of two population-based studies. Psychiatry Res. 2013;205(1-2):151-8.

21. Van P, Meleis Al. Coping with grief after involuntary pregnancy loss: perspectives of African American women. J Obstet Gynecol Neonatal Nurs. 2003;32(1):28-39.

22. Wonch Hill P, Cacciatore J, Shreffler KM, Pritchard KM. The loss of self: the effect of miscarriage, stillbirth, and child death on maternal self-esteem. 
Death Stud. 2017;41(4):226-35. https://doi.org/10.1080/07481187.2016. 1261204.

23. Hall LA, Kotch JB, Browne D, Rayens MK. Self-esteem as a mediator of the effects of stressors and social resources on depressive symptoms in postpartum mothers. Nurs Res. 1996;45(4):231-8.

24. Jesse DE, Swanson MS. Risks and resources associated with antepartum risk for depression among rural southern women. Nurs Res. 2007;56(6):378-86.

25. Kobasa SCO. Stress responses and personality. Gend Stress. 1987;308-329.

26. Ritter C, Hobfoll SE, Lavin J, Cameron RP, Hulsizer MR. Stress, psychosocial resources, and depressive symptomatology during pregnancy in lowincome, inner-city women. Heal Psychol. 2000;19(6):576.

27. Hobfoll SE, Leiberman JR. Personality and social resources in immediate and continued stress resistance among women. J Pers Soc Psychol. 1987;52(1):18

28. Jomeen J, Martin CR. Self-esteem and mental health during early pregnancy. Clin Eff Nurs. 2005;9(1-2):92-5.

29. Karuserci ÖK, Sucu S. Retrospective evaluation of patients treated for ectopic pregnancy: experience of a tertiary center. Rev Bras Ginecol Obstet. 2020:42(12):800-4. https://doi.org/10.1055/s-0040-1718444.

30. Benute GRG, Bordini DCN, Juhas TR, Cabar FR, Pereira PP, de Lucia MCS, Francisco RPV. Depression, stress and guilt are linked to the risk of suicide associated to ectopic pregnancy. Med Exp. 2016;3(3):1-5. https://doi.org/ 10.5935/MedicalExpress.2016.03.07.

31. Farren J, Jalmbrant M, Ameye L, Joash K, Mitchell-Jones N, Tapp S, et al. Post-traumatic stress, anxiety and depression following miscarriage or ectopic pregnancy: a prospective cohort study. BMJ Open. 2016;6:e011864. https://doi.org/10.1136/bmjopen-2016-011864.

32. Hasanpour S, Bani S, Mirghafourvand M, Kochaksarayie FY. Mental health and its personal and social predictors in infertile women. J Caring Sci. 2014:3(1):37.

33. Joshanloo M, Qaedi X. Reinvestigation of the reliability and validity of the Rosenberg self-esteem scale in Iran. Daneshvar Raftar. 2008;15(1):49-56.

34. Mohammadi N. The preliminary study of validity and reliability of Rosenberg's self-esteem scale. J Iran Psychol. 2005;1 (4):55-62.

35. Rajabi G, Bohlol N. Validity and reliability of Rosenberg self-esteem scale in first year student of Shahid Chamran University. J Educ Psychol Res. 2007:3(2):33-48

36. Ebrahimi AMRE, Moulavi H, Mousavi SGh, BornaManesh A, Yaghoubi M. Psychometric properties and factor structure of General Health Questionnaire 28 (GHQ-28) in Iranian psychiatric patients. J Res Behav Sci. 2007;5(1):5-11.

37. Shayan Z, Pourmovahed Z, Najafipour F, Abdoli AM, Mohebpour F, Najafipour S. Factor structure of the general health questionnaire-28 (GHQ-28) from infertile women attending the Yazd Research and Clinical Center for Infertility. Int J Reprod Biomed (Yazd). 2015;13(12):801.

38. Sadeghi A, Sirati-Nir M, Ebadi A, Aliasgari M, Hajiamini Z. The effect of progressive muscle relaxation on pregnant women's general health. Iran J Nurs Midwifery Res. 2015;20(6):655.

39. Matlabi H, Shaghaghi A, Amiri S. A pilot physical activity initiative to improve mental health status amongst Iranian institutionalized older people. Heal Promot Perspect. 2014;4(1):68.
40. Zamanian AZ, Kakouie H, Ayattollahi SMT, Choubineh A, NasI SJ. Prevalence of mental disorders among shift work hospital nurses in Shiraz. Pak J Biol Sci. 2008;11(12):1605-9.

41. Swallow BL, Lindow SW, Masson EA, Hay DM. The use of the General Health Questionnaire (GHQ-28) to estimate prevalence of psychiatric disorder in early pregnancy. Psychol Health Med. 2003;8(2):213-7.

42. Hasani S, Mirghafourvand M, Esmaeilpour K, Sehhati F. The effect of counseling based on health promotion awareness on mental health and self-esteem in women with ectopic pregnancy: a randomized controlled clinical trial. J Matern Neonatal Med. 2019;(just-accepted):1-191.

43. Kamalifard M, Mirghafourvand M, Ranjbar F, Sharajabad FA, Gordani N Relationship of breastfeeding self-efficacy with self-esteem and general health in breastfeeding mothers referred to health centers of Falavarjan City-Iran, 2015. Commun Ment Health J. 2019;55(6):1057-63.

44. Farren J, Jalmbrant M, Ameye L, Joash K, Mitchell-Jones N, Tapp S, et al. Post-traumatic stress anxiety and depression following miscarriage or ectopic pregnancy: a prospective cohort study. BMJ Open. 2016;6(11).

45. Noorbala A, Bagheri Yazdi S, Asadi Lari M, Vaez MM. Mental health status of individuals fifteen years and older in Tehran-Iran. Iran J Psychiatry Clin Psychol. 2011;16(4):479-83.

46. Sowislo JF, Orth U. Does low self-esteem predict depression and anxiety? A meta-analysis of longitudinal studies. Psychol Bull. 2013;139(1):213.

47. Boden JM, Fergusson DM, Horwood L. Does adolescent self-esteem predict later life outcomes? A test of the causal role of self-esteem. Dev Psychopathol. 2008;20(1):319-39.

48. Torkaman M, Farokhzadian J, Miri S, Pouraboili B. The effect of transactional analysis on the self-esteem of imprisoned women: a clinical trial. BMC Psychol. 2020;8(1):1-7.

49. Jiskoot G, Dietz de Loos A, Beerthuizen A, Timman R, Busschbach J, Laven J. Long-term effects of a three-component lifestyle intervention on emotional well-being in women with Polycystic Ovary Syndrome (PCOS): a secondary analysis of a randomized controlled trial. PLOS ONE. 2020;15(6):e0233876.

50. Thomason S, Moghaddam N. Compassion-focused therapies for selfesteem: a systematic review and meta-analysis. Psychol Psychother Theory Res Pract. 2020

51. Alpert B, Field TM, Goldstein S, Perry S. Aerobics enhances cardiovascular fitness and agility in preschoolers. Heal Psychol. 1990;9(1):48.

52. Ekeland E, Heian F, Hagen KB, Abbott J, Nordheim L. Exercise to improve self-esteem in children and young people. Campbell Syst Rev. 2005;1(1):1-52.

53. Liu M, Wu L, Ming Q. How does physical activity intervention improve self-esteem and self-concept in children and adolescents? Evidence from a meta-analysis. PLoS ONE. 2015;10(8):e0134804.

\section{Publisher's Note}

Springer Nature remains neutral with regard to jurisdictional claims in published maps and institutional affiliations.

Ready to submit your research? Choose BMC and benefit from:

- fast, convenient online submission

- thorough peer review by experienced researchers in your field

- rapid publication on acceptance

- support for research data, including large and complex data types

- gold Open Access which fosters wider collaboration and increased citations

- maximum visibility for your research: over 100M website views per year

At BMC, research is always in progress.

Learn more biomedcentral.com/submissions 